\title{
PENGARUH LINGKUNGAN KERJA KERJA DAN KOMITMEN AFEKTIF TERHADAP ORGANIZATIONAL CITIZENSHIP BEHAVIOR (OCB)
}

\author{
Anggun Nilamsari' ${ }^{1}$, Jajuk Herawati ${ }^{2}$ Prayekti $^{3}$ \\ ${ }^{1,2,3}$ Fakultas Ekonomi Universitas Sarjanawiyata Tamansiswa \\ Jl. Kusumanegara No. 157, Muja Muju, Umbulharjo, Yogyakarta \\ E-mail: angunnilamsari85@gmail.com
}

\begin{abstract}
INTISARI
Tujuan pada penelitian ini adalah untuk mengetahui pengaruh variabel lingkungan kerja dan komitmen afektif terhadap organizational citizenship behavior (OCB). Sampel penelitian ini adalah 31 pelaku usaha kecil di Kelurahan Kalibata. Teknik pengambilan sampel menggunakan aksisdental sampling. Data yang digunakan adalah data primer, dengan sumber data diperoleh dari metode penyebaran kuisioner. Analisi data dalam penelitian ini menggunakan regresi berganda.

Hasil penelitian menunjukkan bahwa 1) lingkungan kerja berpengaruh positif terhadap Organizational Citizenship Behavior (OCB) dan 2) komitmen afektif berpengaruh positif terhadap Organizational Citizenship Behavior (OCB),

Katakunci: Lingkungan Kerja, Komitmen Afektif, dan Organizational Citizenship Behavior (OCB).
\end{abstract}

\section{ABSTRACT}

The purpose of this study was to determine the effect of work environment variables and affective commitment on organizational citizenship behavior (OCB). The sample of this study was 31 small businesses in the Kalibata Village. The sampling technique uses aksisdental sampling. The data used are primary data, with data sources obtained from the questionnaire distribution method. Data analysis in this study uses multiple regression.

The results showed that 1) the work environment had a positive effect on Organizational Citizenship Behavior (OCB) and 2) affective commitment had a positive effect on Organizational Citizenship Behavior (OCB).

Keywords: Job Satisfaction, Affective Commitment, and Organizational Citizenship Behavior $(O C B)$.

\section{PENDAHULUAN}

Perkembangan bisnis di Indoneisa dari waktu ke waktu menuju kearah yang lebih baik, hal ini terbukti dengan tumbuhnya banyak perusahaan baik perusahaan kecil maupun perusahaan besar. Perusahaan merupakan tempat berkumpulnya orang-orang yang memiliki tujuan yang sama untuk mencapai tujuan bersama (Hidayat dan Kusumawati, 2019). Perusahaan atau usaha berdiri memiliki tujuan dan fokus bidang yang berbeda-beda. Bagi usaha yang memiliki bidang bisnis yang sama maka akan timbul persaiangan yang ketat antar perusahaan. Persaingan tersebut banyak terjadi di seluruh daerah di Indonesia, salah satunya DKI Jakarta. DKI Jakarta merupakan daerah sentral di Indonesia karena merupakan Ibu Kota Negara Republik Indonesia, selain itu DKI Jakarta merupakan sentral ekonomi Indonesia. DKI Jakarta menjadi daerah sentral ekonomi Indonesia terbukti daerah tersebut memiliki pertumbuhan ekonominya yang paling tinggi se Indonesia (Badan Pusat Statistik Indonesia, 2019). Pertumbuhan ekonomi yang tinggi ini disumbangkan oleh pendapatan asli daerah terbut yang didapatkan dari banyaknya perusahaan yang tumbuh di daerah tersebut. Pertumbuhan perusahaan atau usaha menurut para ahli mengindikasikan keberhasilan perusahaan atau usaha. Salah satu kunci keberhasilan perusahaan di era globaliasi yaitu 
sejauh mana warga organisasi atau karyawan perusahaan secara sinergi mampu mencapat tujuan perusahaan (Kailola, 2018), hal tersebut menunjukkan bahwa pentingnya peran sumber daya manusia (SDM) dalam keberhasilan perusahaan atau usaha.

Sumber daya manusia (SDM) menempati posisi strategis diantara sumber daya yang lain seperti sumber daya finansial dan lain-lain. Banyak sumber daya didalam sebuah perusahaan, tetapi tanpa sumber daya manusia (SDM), sumber daya yang lain dimiliki oleh perusahaan tidak dapat dimanfaatkan. Perusahaan atau entitas yang baik, dalam perkembangannya pastilah menitik beratkan pada sumber daya manusia (human resources) guna menjalankan fungsinya dengan optimal. Kajian-kajian perilaku perusahaan menunjukkan bahwa ada interaksi feedback atau timbal balik dari setiap induvidu ternyata tidak selalu sama walaupun diberikan stimulus yang smaa dari dinamika kelompok ataupun sistem organisasi, karena adanya perbedaan-perbedaan induvidu.induvidu dalam perusahaan dikatakan baik tidak dilihat dari kemampuan saja melainkan dari kepribadianya pula. Kepribadian induvidu dalam perusahaan atau entitas sangat bervariasi, hal ini dipostulatkan membentuk variasi perilaku dalam perusahaan atau entitas termasuk perilaku kerja. Walaupun tiap organisasi memiliki uraian tugas, SOP dan struktur organisasi, variasi kepribadian induvidu dalam organisasi membuat cenderung variasi perilaku kerja yang berbeda. Kepribadian merupakan dimensi dari kepribadian yang merupakan kencenderungan emosional dan keterikatan dengan perusahaan atau usaha yang sering disebut dengan komitmen affektif.

Berdasarkan penjelasan sebelumnya, maka peneliti tertarik melakukan penelitian kembali dengan terinspirasi penelitian yang dilakukan oleh Setyoasih dan Salehudin (2019), adapun perbedaan penelitian ini terdahulu dengan penelitian saat ini adalah penelitian ini menambahkan variabel lingkungan kerja. Peneliti menambahkan lingkungan kerja karena ingin mengetahui keadaan lingkungan kerja yang sedang tidak menentu saat ini karena pandemi memiliki hubungan dengan Organizational Citizensh ip Behavior (OCB) atau sikap loyal terhadap perusahaan. Oleh karena itu judul penelilitian ini adalah Pengaruh Lingkungan Kerja dan Komitmen Afektif terhadap Organizational Citizenship Behavior (OCB).

\section{TINJAUAN PUSTAKA DAN PENGEMBANGAN HIPOTESIS}

Lingkungan kerja yang baik adalah lingkungan kerja yang dapat memberikan kenyamanan yang tinggi bagi karyawan dalam bekerja, baik itu lingkungan secara fisik dan lingkungan kerja secara non fisik. Lingkungn kerja Fisik merupakan semua keadaan yang mempunyai bentuk fisik yang terdapat disekitar tempat kerja yang dapat memperngaruhi karyawan baik secara langkung maupun tidak langsunng. Imdikator lingkungan kerja fisik tersebut adalah sebagai berikut: Penerangan, Suhu Udara, Kebisingan, Dekorasi, dan Keamanan. Lingkungan kerja non fisik merupakan semua keadaan yang berkaiatan atau berhubungan dengan pekerjaan, baik hubungan dengan atasan maupun hubungan sesama rekan kerja, ataupun hubungan dengan bawahan. Imdikator lingkungan kerja non fisik tersebut adalah sebagai berikut: Hubungan Kerja dengan Atasan, Hubungan dengan rekan kerja, dan Hubungan atasan dengan bawahan

Komitmen afektif merupakan keterikatan antara pegawai dalam sebuah entitas yang berasal dari ikatan emosional, hal ini karena adanya ikatan emosional dari kenyamanan dan nilai-nilai pribadi dengan tujuan organisasi atau perusahaan (Paramaartha, 2019). Terdapat indikator untuk mengukur komitmen afektif (Meyer dan Allen, 1993 dalam Felicia, 2017) sebagai berikut adalah karakteristik organisasi yaitu hubungan antara komitmen organisasi dan struktur organisasi, karakteristik personal yaitu terdiri dari kebutuhan untuk pencapaian prestasi, afilliasi dan kebebasan, serta ketertarikan dalam kehidupan bekerja telah ditemukan berhubungan dengan komitmen organisasi, dan pengalaman kerja yaitu Pengalaman kerja merupakan suatu dorongan sosial dan menghadirkan suatu ketertarikan psikologis yang dibentuk dalam suatu organisasi. 
Organizational citizenship behavior (OCB) adalah "work behavior that exceeds the job requirements and contribute to organizational success," perilaku kerja yang melebihi persyaratan kerja dan turut berperan dalam kesuksesan organisasi (Daft dan Lane 2009: 378 dalam Vania dan Purba, 2014). Terdapat lima dimensi Organizational Citizenship Behavior (OCB) (Organ et al, 2006, p. 18 dalam dalam Irshad (2014), diantaranya yaitu: 1) Altruism adalah perilaku seorang karyawan yang merujuk pada perilaku membantu serta menolong rekan kerja yang mengalami kesulitan dalam pekerjaan, 2) Conscientiousnes adalah perilaku seorang karyawan yang merujuk pada kedisiplinan karyawan terhadap aturan-aturan atau SOP yang telah ditetapkan perusahaan, 3) Sportmanship adalah perilaku karyawan yang merujuk pada toleransi terhadap persoalan yang tidak perlu diperdebatkan dalam keadaan apapun, 4) Courtesy adalah perilaku karyawan dalam perusahaan dengan selalu menjaga hubungan baik antar karyawan supaya terhindar dari konflik, 5) Civic Virtue adalahperilaku karyawan terhadap perusahaan yang merujuk pada kontribusi karyawan terhadap perusahaan dengan penuh tanggung jawab dan membangun.

\section{Pengembangan Hipotesis}

Apabila karyawan merasakan lingkungan kerjanya baik, maka karyawan cenderung untuk berperilaku baik, karena apabila lingkungan kerja dirasa nyaman maka akan memberikan emosi yang stabil seseorang di dalam pekerjaannya.

H1 : Lingkungan kerja berperngaruh positif terhadap Organizational Citizenship Behavior (OCB).

Komitmen afektif dapat mendorong karyawan agar tetap bekerja dalam perusahaan, karena karyawan telah merasa yakin dan sependapat dengan nilai-nilai serta tujuan perusahaan. Karyawan yang memiliki komitmen afektif yang tinggi mereka akan mendukung tujuan perusahaan serta mereka bersedia untuk membantu agar tujuan perusahaan dapat tercapai.

H2: Terdapat pengaruh positif komitmen afktif terhadap Organizational Citizenship Behavior (OCB).

\section{Kerangka Pemikiran Dan Pengembangan Hipotesis}

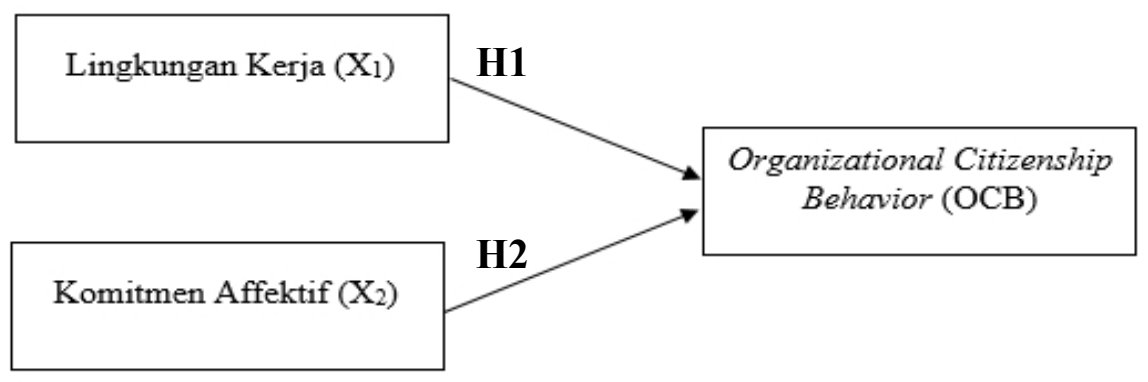

\section{Gambar 1.KerangkaPikir Penelitian}

\section{METODE PENELITIAN}

Populasi merupakan keseluruhan dari objek penelitian yang akan diteliti (Hadi, 2009: 45). Populasi dalam penelitian ini adalah 31 karyawan dan pelaku usaha kecil Kelurahan Kalibata di DKI Jakarta. Pengambilan sampel dilakukan oleh peneliti untuk mendapatkan sampel yang tepat untuk penelitian. Pengambilan sampel dalam penelitian ini mengunakan teknik pengambilan sampel aksisdental sampling yaitu responden yang bertemu atau dijumpai dan bersedia menjawab kuesioner adalah sampel penelitian. Sampel adalah bagian atau wakil populasi yang memiliki karakteristik sama dengan populasinya, ambil sebagai sumber data 
penelitian (Hadi, 2009: 45). Sampel dalam penelitian adalah seluruh pelaku usaha kecil Kelurahan Kalibata di DKI Jakarta sebanyak 31 responden, sehingga menggunakan sensus.

\section{HASIL DAN PEMBAHASAN}

\section{Uji Validitas}

Uji Validitas digunakan untuk mengukur sah atau valid tidaknya suatu kuesioner. Item kuesioner dikatakan valid jika $r$ hitung $>r$ tabel. Uji validitas dalam penelitian ini adalah sebagai berikut:

Tabel 1 Uji Validitas Lingkungan Kerja $\left(\mathrm{X}_{1}\right)$

\begin{tabular}{llll}
\hline Indikator & r-hitung & r-tabel $(\mathbf{0 , 0 5})$ & Keterangan \\
\hline Item 1 & 0,600 & 0,3009 & Valid \\
Item 2 & 0,663 & 0,3009 & Valid \\
Item 3 & 0,704 & 0,3009 & Valid \\
Item 4 & 0,730 & 0,3009 & Valid \\
Item 5 & 0,619 & 0,3009 & Valid \\
Item 6 & 0,690 & 0,3009 & Valid \\
Item 7 & 0,727 & 0,3009 & Valid \\
Item 8 & 0,753 & 0,3009 & Valid \\
Item 9 & 0,643 & 0,3009 & Valid \\
Item 10 & 0,754 & 0,3009 & Valid \\
Item 11 & 0,803 & 0,3009 & Valid \\
\hline
\end{tabular}

Sumber: data primer diolah, 2020

Berdasarkan tabel 1 sebelumnya menunjukkan bahwa $r$ hitung $>r$ tabel. Hal tersebut menunjukkan bahwa seluruh 11 item pernyataan variabel kepuasan kerja dikatakan valid, karena seluruh $r$ hitung $>r$ tabel.

Tabel 2 Uji Validitas Komitmen Afektif $\left(\mathrm{X}_{2}\right)$

\begin{tabular}{llll}
\hline Indikator & r-hitung & r-tabel $(\mathbf{0 , 0 5})$ & Keterangan \\
\hline Item 1 & 0,663 & 0,3009 & Valid \\
Item 2 & 0,727 & 0,3009 & Valid \\
Item 3 & 0,708 & 0,3009 & Valid \\
Item 4 & 0,786 & 0,3009 & Valid \\
Item 5 & 0,420 & 0,3009 & Valid \\
Item 6 & 0,570 & 0,3009 & Valid \\
Item 7 & 0,728 & 0,3009 & Valid \\
Item 8 & 0,521 & 0,3009 & Valid \\
Item 9 & 0,698 & 0,3009 & Valid \\
Item 10 & 0,685 & 0,3009 & Valid \\
Item 11 & 0,632 & 0,3009 & Valid \\
Item 12 & 0,793 & 0,3009 & Valid \\
\hline
\end{tabular}

Sumber: data primer diolah, 2020

Berdasarkan tabel 1 sebelumnya menunjukkan bahwa $\mathrm{r}$ hitung $>\mathrm{r}$ tabel. Hal tersebut menunjukkan bahwa seluruh 12 item pernyataan variabel kepuasan kerja dikatakan valid, karena seluruh $r$ hitung $>\mathrm{r}$ tabel. 


\begin{tabular}{llll}
\hline Indikator & r-hitung & r-tabel $\mathbf{( 0 , 0 5 )}$ & Keterangan \\
\hline Item 1 & 0,789 & 0,3009 & Valid \\
Item 2 & 0,487 & 0,3009 & Valid \\
Item 3 & 0,754 & 0,3009 & Valid \\
Item 4 & 0,847 & 0,3009 & Valid \\
Item 5 & 0,614 & 0,3009 & Valid \\
Item 6 & 0,778 & 0,3009 & Valid \\
Item 7 & 0,792 & 0,3009 & Valid \\
Item 8 & 0,607 & 0,3009 & Valid \\
Item 9 & 0,749 & 0,3009 & Valid \\
Item 10 & 0,751 & 0,3009 & Valid \\
\hline
\end{tabular}

Sumber: data primer diolah, 2020

Berdasarkan tabel 4.10 sebelumnya menunjukkan bahwa $\mathrm{r}$ hitung $>\mathrm{r}$ tabel. Hal tersebut menunjukkan bahwa seluruh 10 item pernyataan variabel kepuasan kerja dikatakan valid, karena seluruh $r$ hitung $>r$ tabel.

\section{Uji Reabilitas}

Uji reliabilitas bertujuan untuk menguji konsistensi jawaban responden sehingga terhindar dari bias. Instrument dikatakan reliabel jika nilai Cornbach's Alpha > 0,7 (Ghozali, 2016: 52). Hasil Uji reliabilitas dalam penelitian ini adalah sebagai berikut:

Tabel 4 Uji Reliabilitas

\begin{tabular}{llll}
\hline Variabel & $\begin{array}{l}\text { Cornbach's } \\
\text { Alpha }\end{array}$ & $\begin{array}{l}\text { Nilai } \\
\text { minimum }\end{array}$ & Keterangan \\
\hline Lingkungan Kerja & 0,893 & 0,70 & Reliabel \\
Komitmen Afektif & 0,878 & 0,70 & Reliabel \\
OCB & 0,887 & 0,70 & Reliabel \\
\hline
\end{tabular}

Sumber: data primer diolah, 2020

Berdasarkan tabel 4 sebelumnya, maka dapat disimpulkan nilai Cronbach's Alpha $>0,7$. Hal tersebut menunjukkan seluruh jawaban responden reliabel.

\section{Uji Asumsi Klasik}

Uji asumsi klasik dilakukan sebelum melakukan uji regresi berganda bertujuan untuk menghasilkan hasil analisis yang terhindar dari bias (Ghozali, 2019: 94). Uji asumsi klasik dalam penelitian ini terdiri dari uji normalitas, uji multikolonieritas, dan uji heterokedastisitas. Hasil uji asumsi klasik dalam penelitian ini adalah sebagai berikut:

\section{Uji Normalitas}

Uji normalitas bertujuan untuk menguji residual data memiliki distribusi normal. Uji normalitas dalam penelitian ini menggunakan alat uji Kolmogorov Smirnov, dengan kriteria pengambilan keputusan jika nila Asymp. Sig.> 0,05 (alpha) maka berdistribusi normal. Uji Normalitas dalam penelitian ini adalah sebagai berikut:

\section{Tabel 5 Uji Normalitas}

\begin{tabular}{lll}
\hline Kolmogorow-Smirnov & Asymp. Sig. & Keterangan \\
\hline 0,123 & 0,200 & Distribusi Normal \\
\hline
\end{tabular}

Sumber: data primer diolah, 2020 
Berdasarkan tabel 4.12 sebelumnya menunjukkan nilai Asymp. Sig. sebesar 0,200>0,05 Alpha, Hal tersebut menunjukkan bahwa residual data variabel lingkungan kerja dan komitmen afektif terhadap Organizational Citizenship Behavior berdistribusi normal.

\section{Uji Multikolinieritas}

Uji multikolinieritas dalam penelitian ini bertujuan untuk menguji suatu hubungan atau korelasi antar variabel bebas (independen), Uji multikolinieritas dalam penelitian ini diukur dengan menggunakan nilai tolerance dan VIF. Hasil uji multikolinieritas dalam penelitian ini adalah sebagai berikut:

Tabel 6 Uji Multikolonieritas

\begin{tabular}{llll}
\hline & Tolerance & VIF & Keterangan \\
\hline Lingkungan Kerja & 0,327 & 3,062 & $\begin{array}{l}\text { Tidak } \\
\text { Multikolonieritas }\end{array}$ \\
Komitmen Afektif & 0,327 & 1,062 & $\begin{array}{l}\text { Tidak } \\
\text { Multikolonieritas }\end{array}$ \\
\hline
\end{tabular}

Sumber: data primer diolah, 2020

Berdasarkan tabel 4.13 sebelumnya, maka menunjukkan nilai tolerance $>0,10$ dan nilai VIF $<$ 10. Hal tersebut menunjukkan bahwa seluruh variabel independen yang terdiri dari lingkungan kerja dan komitmen afektif terbebas dari multikolonieritas.

\section{Uji Heterokedastisitas}

Uji heteroskedastisitas bertujuan untuk menguji bahwa dalam model regresi terjadi ketidaksamaan variance dan residual satu pengamatan ke pengamatan yang lain, jika variance dari residual satu pengamatan ke pengamatan lain tetap disebut homoskedastisitas dan jika berbeda disebut heteroskedastisitas. Uji heteroskedastisitas dalam penelitian ini menggunakan Uji Glejser dengan meregresi nilai Absolut Residual. Hasil uji heterokedastisitas dengan menggunakan alat Uji Glejser dalam penelitian ini adalah sebagai berikut:

\section{Tabel 7 Uji Heterokedastisitas}

\begin{tabular}{llll}
\hline & Sig. & Alpha & Keterangan \\
\hline Lingkungan Kerja & 0,269 & 0,05 & Tidak Terjadi Heterokedastisitas \\
Komitmen Afektif & 0,428 & 0,05 & Tidak Terjadi Heterokedastisitas \\
\hline
\end{tabular}

Sumber: data primer diolah, 2020

Berdasarkan tabel 7 sebelumnya, maka menunjukkan nilaiSig. $>0,05$. Hal tersebut menunjukkan bahwa seluruh variabel terbebas dari Heterokedastisitas.

\section{Uji Regresi Linear Berganda}

Regresi berganda bertujuan mengetahui pengaruh atau kontribusi variabel independen yang lebih dari satu variabel terhadap dependen. Variabel indepden dalam penelitian ini terdiri dari lingkungan kerja dan komitmen afektif terhadap variabel dependen organizational citizenship behavior. Hasil uji regresi berganda dalam penelitian ini dengan bantuan SPSS sebagai berikut: 
Tabel 8 Uji Regresi Berganda

\begin{tabular}{lllll}
\hline & Koefisien (B) & Sig. & Alpha & Keterangan \\
\hline Constant & 1,145 & 0,769 & & \\
Lingkungan Kerja & 0,289 & 0,039 & 0,05 & $\mathbf{H}_{1}$ diterima \\
Komitmen Afektif & 0,599 & 0,000 & 0,05 & $\mathbf{H}_{2}$ diterima \\
\hline
\end{tabular}

Sumber: data primer diolah, 2020

Berdasarkan tabel 8 diatas dapat dirumuskan suatu persamaan regresi untuk mengetahui pengaruh atau kontribusi lingkungan kerja dan komitmen afektif terhadap organizational citizenship behavior (OCB) sebagai berikut:

$$
\mathrm{Y}=1,145+0,289 \mathrm{X}_{1}+0,599 \mathrm{X}_{2}+\mathrm{e}
$$

$\mathrm{Y}=$ Organizational Citizenship Behavior (OCB)

$\alpha=$ Konstanta

b1,b2 = Koefisien Regresi

$\mathrm{X}_{1}=$ Lingkungan Kerja

$\mathrm{X}_{2}=$ Komitmen Afektif

$\mathrm{e}=$ Standart error

Koefisien-koefisien persamaan regresi linear berganda diatas dapat diartikan sebagai berikut:

Nilai konstanta sebesar 1,145 nilai tersebut mengindikasikan tanpa adanya pengaruh variabel independen yang digunakan pada penelitian ini, maka nilai Organizational Citizenship Behavior (OCB) sebesar 1,145.

Koefisien regresi lingkungan kerja untuk variabel $\mathrm{X}_{1}$ sebesar 0,289 yang artinya bahwa setiap peningkatan lingkungan kerja naik satu (1) satuan akan meningkatkan Organizational Citizenship Behavior (OCB) sebesar 0,289 dengan asumsi variabel lain konstan.

Koefisien regresi komitmen afektif untuk variabel $\mathrm{X}_{2}$ sebesar 0,599 yang artinya bahwa setiap peningkatan komitmen afektif naik satu (1) satuan akan meningkatkan Organizational Citizenship Behavior (OCB) sebesar 0,599 dengan asumsi variabel lain konstan.

\section{Uji Hipotesis}

Uji hipotesis dalam penelitian ini bertujuan mengetahui persentase kemampuan variabel independen dalam menjelaskan variabel dependen, serta mengetahui hubungan secara simultan dan parsial variabel independen terhadap dependen. Adapun untuk menguji hipotesis yang terdri dari uji koefisein determinasi, uji simultan, dan uji parsial dilakukan dalam penelitian ini adalah sebagai berikut:

\section{Koefisien Determinasi $\left(\mathbf{R}^{2}\right)$}

Koefisien determinasi $\left(\mathrm{R}^{2}\right)$ pada intinya mengukur seberapa jauh kemampuan model dalam menerangkan variasi variabel dependen. Uji koefisien determinasi dalam penelitian ini menggunakan nilai Adjusted $R$ Square kemudian dikali seratus persen untuk mengetahui kemampuan variabel independen menjelaskan dependen. Hasil uji koefisien determinasi $\left(\mathrm{R}^{2}\right)$ sebagai berikut: 


\section{Tabel 9 Hasil Uji Koefisien determinasi $\left(\mathbf{R}^{2}\right)$}

\begin{tabular}{lc}
\hline & Summary \\
\hline Adjusted R Square & 0,802 \\
\hline Sumber: data primer diolah, 2020
\end{tabular}

Sumber: data primer diolah, 2020

Berdasarkan Tabel 9 diatas menunjukan bahwa R-square (koefisien determinasi) sebesar 0,802, Hal ini berarti 80,2\% variabel Organizational Citizenship Behavior (OCB) dijelaskan oleh variabel independen yang terdiri dari lingkungan kerja dan komitmen afektif dalam penelitian ini, sedangkan sisanya 19,8\% dijelaskan dipengaruhi oleh variabel lain.

\section{Uji signifikan simultan (F)}

Uji statistik F pada dasarnya menunjukkan semua variabel independen atau bebas yang dimasukkan dalam model mempunyai pengaruh secara bersam-sama atau simultan terhadap variabel dependen (Ghozali, 2016: 98), variabel memiliki pengaruh jika nilai signifikan < 0,05 (alpha). Hasil uji signifikan simultan F dalam penelitian ini adalah sebagai berikut:

Tabel 10 Hasil Uji Signifikansi Simultan (F)

\begin{tabular}{lll}
\hline Signifikansi & Alpha & Keputusan \\
0,00 & 0,05 & Diterima \\
\hline
\end{tabular}

Sumber: data primer diolah, 2020

Berdasarkan Tabel 10 di atas menunjukan bahwa nilai Sig. sebesar $0.000<0.05$, hasil tersebut menunjukkan bahwa niali signifikan lebih kecil dari pada alpha. Berdasarkan hasil tersebut dinyatakan variabel independen yang terdiri dari lingkungan kerja dan komitmen afektif berpengaruh sama-sama atau simultan terhadap variabel dependen Organizational Citizenship Behavior (OCB).

\section{Hasil Uji Secara Parsial (Uji t)}

Uji ststistik t pada dasarnya menunjukkan seberapa jauh pengaruh satu variabel penjelas independen secara individual dalam menerangkan variabel dependen (Ghozali, 2016: 98). Hasil uji signifikan parsial t sebagai berikut:

Tabel 11 Hasil Uji Secara Parsial (Uji t)

\begin{tabular}{lllll}
\hline & Koefisien (B) & Sig. & Alpha & Keterangan \\
\hline Constant & 1,145 & 0,769 & & \\
Lingkungan Kerja & 0,289 & 0,039 & 0,05 & $\mathbf{H}_{\mathbf{1}}$ diterima \\
Komitmen Afektif & 0,599 & 0,000 & 0,05 & $\mathbf{H}_{\mathbf{2}}$ diterima \\
\hline
\end{tabular}

Sumber: Data Sekunder Diolah (2019)

Berdasarkan Tabel diatas menunjukan hasil statistik $t$ antara pengaruh variabel independen dengan variabel dependen. Hasil uji t dalam penelitian ini adalah sebagai berikut:

\section{Hipotesis Pertama}

Variabel lingkungan kerja memiliki nilai koefisien sebesar 0,289 dan tingkat signifikan sebesar 0.039. Tingkat signifikan tersebut lebih kecil dari $<0.05$ yang berarti $\mathrm{H} 1$ di terima, sehingga dapat dikatakan bahwa variabel kepuasan kerja berpengaruh positif terhadap Organizational Citizenship Behavior (OCB). 


\section{Hipotesis Kedua}

Variabel komitmen afektif memiliki nilai koefisien sebesar 0,599 dan tingkat signifikan sebesar 0.000 . Tingkat signifikan tersebut lebih kecil dari $<0.05$ yang berarti $\mathrm{H} 1$ di terima, sehingga dapat dikatakan bahwa variabel komitmen afektif berpengaruh positif terhadap Organizational Citizenship Behavior (OCB).

\section{PEMBAHASAN}

Pengaruh Lingkungan Kerja Terhadap Organizational Citizenship Behavior (OCB).

Berdasarkan Hasil Pengujian Regresi Berganda dalam penelitian ini dapat disimpulkan $\mathrm{Ha}_{1}$ diterima, yang artinya lingkungan kerja berpengaruh positif terhadap Organizational Citizenship Behavior (OCB). Lingkungan kerja merupakan lingkungan sekitar para karyawan atau pegawai menjalankan aktivitasnya dalam bekerja, lingkungan kerja yang aman dan kondusif membuat karyawan dapat bekerja secara optimal (Wulandari dan Prayitno, 2017). Hal tersebut menunjukkan jika pegawai menyenangi lingkungan kerja dimana dia bekerja, maka pegawai atau karyawan akan betah ditempat kerjanya untuk. Jika pegawai menyenangi lingkungan kerja dimana dia bekerja, maka pegawai tersebut akan betah ditempat kerjanya untuk melakukan aktivitasnya. Sehingga waktu kerja yang dipergunakan secara efektif dan optimas prestasi kerja pegawai juga tinggi. Dengan kata lain lingkungan kerja yang mendukung, maka komitmen organisasi karyawan akan muncul kerena karyawan betah di tempat pekerjaan sehingga loyalitas terhadap perusahaan semakin meningkat. Hal ini didukung oleh penelitian yang dilakukan oleh Kailola (2018) yang menyatakan bahwa lingkungan kerja berpengaruh positif terhadap Organizational Citizenship Behavior (OCB).

\section{Pengaruh Komitmen Afektif Terhadap Organizational Citizenship Behavior (OCB).}

Berdasarkan Hasil Pengujian Regresi Berganda dalam penelitian ini dapat disimpulkan $\mathrm{Ha}_{2}$ diterima, yang artinya komitmen afektif berpengaruh positif terhadap Organizational Citizenship Behavior (OCB). Komitmen afektif merupakan keterikatan antara pegawai dalam sebuah entitas yang berasal dari ikatan emosional, hal ini karena adanya ikatan emosional dari kenyamanan dan nilai-nilai pribadi dengan tujuan organisasi atau perusahaan (Paramaartha, 2019). Komitmen yang dimiliki karyawan terhadap perusahaannya akan menentukan bagaimana hasil yang diperoleh perusahaan dalam mencapai tujuan. Oleh karena itu komitmen afektif yang dimiliki karuawan menjadi salah satu faktor penting tercapainya tujuan dan sikap loyal terhadap perusahaan, selain itu faktor lain membuat loyal terhadap perusahaan yaitu lingkungan kerja. Hal ini didukung oleh penelitian yang dilakukan oleh Kailola (2018) yang menyatakan bahwa komitmen affektif berpengaruh positif terhadap Organizational Citizenship Behavior (OCB).

\section{PENUTUP}

Berdasarkan penelitian yang telah dilakukan peneliti pada seluruh karyawan dan pelaku usaha Kelurahan Kalibata DKI Jakarta mengenai pengaruh lingkungan kerja dan komitmen afektif terhadap Organizational Citizenship Behavior (OCB), maka dapat ditarik kesimpulan dalam penelitian ini adalah sebagai berikut:

Lingkungan kerja berpengaruh positif terhadap Organizational Citizenship Behavior (OCB), sehingga jika lingkungan kerja meningkat maka Organizational Citizenship Behavior (OCB) meningkat.

Komitmen afektif berpengaruh positif terhadap Organizational Citizenship Behavior (OCB), sehingga jika komitmen afektif meningkat maka Organizational Citizenship Behavior (OCB) meningkat. 


\section{Saran}

Berdasarkan penelitian yang dilakukan, maka terdapat beberapa saran untuk para pemilik usaha dan peneliti berikutnya:

Lingkungan kerja yang baik adalah lingkungan kerja yang dapat memberikan kenyamanan yang tinggi bagi karyawan dalam bekerja, baik itu lingkungan secara fisik dan lingkungan kerja secara non fisik. Hasil penelitian ini menunjukkan bahwa lingkungan berpengaruh terhadap Organizational Citizenship Behavior (OCB) atau sikap loyalitas, sehingga harapanya para pelaku usaha tetap menjaga lingkungan kerja yang kondusif baik lingkungan fisik mau non fisik agar karyawan mampu mengelaurkan kinerja terbaik dan bersifat loyal terhadap tujuan usaha.

Penelitian berikutnya harapanya dapat menambahakan variabel baru, sehingga hasil penelitian lebih dapat digeneralisasikan.

\section{DAFTAR PUSTAKA}

Arif Hidayat dan Ratna Kusumawati. (2017). Pengaruh Komitmen Organisasi dan Kepuasan Kerja Terhadap Organizational CitizenshipBehavior (OCB). Jurnal Fakultas Ekonomi Wahid Hasyim Semarang.

Felicia, A., Petra, U. K., \& Siwalankerto, J. (n.d.). No Title. 62(3), 368-370.

Ghozali, I. (2016). Aplikasi Analisis Multivariate dengan Program IBM SPSS 23.

Hadi, S. (2009). Metodologi Penelitian Kuantitatif. Yogyakarta: EKONISIA.

Irshad, R. (2014). How Transformational Leadership is related to Organizational Citizenship Behavior? The. 8(2), 413-425.

Kailola, S. (2018). Pengaruh Kepribadian dan Lingkungan Kerja Terhadap Organizational Citizenship Behavior (OCB). Jurnal Manis, 2.

Paramaartha, D. N. (2019). Jakarta , 18 Februari 2019 Pengaruh Perceived Organizational Support ( POS ), Keadilan Interpersonal, dan Komitmen Afektif terhadap Organizational Citizenship Behavior ( OCB ) Guru Sekolah Menengah Atas BPK PENABUR di Jabodetabek. (September). https://doi.org/10.13140/RG.2.2.16300.62080

Setyoasih, I. S., Salehudin, I., Ekonomi, F., \& Indonesia, U. (n.d.). Analisis Pengaruh Kepuasan Kerja dan Komitmen Afektif Organisasi Terhadap Perilaku Organizational Citizenship Behavior dan Perilaku Berbagi Pengetahuan Pada Guru.

Vania, Lidya dan Purba, S. D. (2014). Pengaruh Job Satisfaction Terhadap Organizational Citizenship Behavior (OCB) Dengan Organizational Commitment Sebagai Variabel Intervening. Jurnal Fakultas Ekonomi Universitas Katolik Indonesia.

Wulandari, D. A., \& Prayitno, A. (2017). Pengaruh Motivasi Kerja Dan Lingkungan Kerja Terhadap Organizational Citizenship Behavior Dengan Komitmen Organisasi Sebagai Variabel Intervening. Jurnal Penelitan Ekonomi Dan Bisnis, 2(1), 46-57. https://doi.org/10.33633/jpeb.v2i1.2234 